\title{
INSTITUTIONS, COMMUNITY, AND PEOPLE: An Evaluation of a Longitudinal Digital Divide Experience
}

\author{
Barbara J. Crump \\ Massey University \\ Wellington, New Zealand
}

\begin{abstract}
A community computing center was established in late 2001 in a city council high-rise apartment block in Wellington. New Zealand's capital city. The center was one of five computing hubs (centers) of the Smart Newtown Project, established with economic and social inclusion objectives, in the lower socio-economic suburb of Newtown. The project aim was to reduce inequalities of access to information and communications technology (ICT). A partnership approach was adopted that included multiple stakeholders: city council employees and councillors, a communications trust, universities, staff of a computer corporation, and some apartment residents. After 4 years of operation, the center was closed and remains so at the time of writing. Using a theoretical framework that includes Warschauer's (2003) model of ICT for social inclusion, the concept of social capital, and Oldenburg's (1991) third place, this paper examines reasons for the center's closure. The main findings reveal that low social capital and the inadequate support of social resources in the form of the community and an institution were key factors in the closure of this initiative. Recommendations are made for implementing future projects.
\end{abstract}

Keywords Community computing, sustainability, ICT, social inclusion, social capital, digital divide

\section{INTRODUCTION}

In May 2005, the New Zealand government launched its digital strategy with the aim of "creating a digital future for all New Zealanders whether they are at home,

Please use the following format when citing this chapter:

Crump, B.J., 2006, in IFIP International Federation for Information Processing, Volume 208, Social Inclusion: Societal and Organizational Implications for Information Systems, eds. Trauth, E., Howcroft, D., Butler, T., Fitzgerald, B., DeGross, J., (Boston: Springer), pp. 333-346. 
school, work or in the community." The strategy aims at positioning New Zealand as a world leader in using information and technology to realize its economic, social, environmental, and cultural goals, to the benefit of all its people. The focus is on spreading the benefits of information and communications technology (ICT) ${ }^{2}$ right across the economy and "ensuring all Kiwis [New Zealanders] can participate." ${ }^{3}$ The community sector is one of the three "agents of change" identified as necessary for meeting the New Zealand government's goal of raising people's awareness of the potential of ICT. Business and government are the other two agents and these, together with the enablers of content, connection, and confidence will, it is believed, form the foundation for realizing the full benefits of ICT.

Nearly 5 years prior to the launch of the digital strategy a partnership was formed between the Wellington Regional Economic Development Agency (WREDA, an agency representing the Wellington region's local government councils), and Fujitsu New Zealand Ltd., a computer corporation. Employees of these organizations, together with some tenants of a council high-rise apartment block, were interested in addressing economic and social inequalities that they believed could arise from disadvantaged people being excluded from the information society. Many of them were aware of digital divide strategies that had been implemented within low-income, highunemployment, and ethnically diverse communities, characteristics of groups identified as those more likely than others to be left behind in the information revolution. Some of these initiatives focused on the establishment of community computing centers that offered free Internet access and introductory classes and there was enthusiasm from Fujitsu and some agency employees for establishing such a center at the Newtown Park Flats (NPF). Representatives of the Wellington City Council and WREDA called two consultative meetings at the flats (apartments) outlining the proposal to tenants interested in participating in this project. Although there was a very low attendance of tenants at the two meetings (representing about 5 percent and 2 percent of the total tenant population respectively), those present expressed interest in this community project, ultimately resulting in the establishment of the computing center at NPF. This center was the second to be launched as part of the five-hub project planned for the Smart Newtown Project.

\section{THE SMART NEWTOWN PROJECT}

The aim for the Smart Newtown Project was to narrow the digital divide and had specific objectives of

- Improving educational achievement and interest in participation in further education

'Community Net, Community Centre News, "The Digital Strategy-Creating a Digital Future," http://www.community.net.nz/CommunityCentre/News/National/digital-strategyannounce.htm.

${ }^{2} \mathrm{~A}$ term that includes technologies such as computers and communications such as satellites, mobile phones, and the Internet to process, transmit, and store data.

3“"The Digital Strategy: Creating Our Digital Future," 2005, www.digitalstrategy.govt.nz. 
- Improving short and long term employment prospects

- Developing ICT skill levels among disadvantaged groups

- Enhancing economic and social benefits for the wider community

- Strengthening intra-family relationships and cooperation

- Extending social networks and greater community interaction

- Improving opportunities for residents' expression of cultural heritage

- Improving flow of information between home and school

Newtown was chosen as the pilot community because of its diverse needs and breadth of ethnic groups - 46 percent come from 41 ethnic groups other than Maori or Pakeha (European New Zealanders) and less than 40 percent of households had access to the Internet (2001 census statistics, cited in Smart Newtown Project 2003). The project partnership model included multiple stakeholders beyond the council and computer corporation; there were also representatives from a communications-based charitable trust, three educational institutions (a polytechnic and two universities), and community organizations.

By 2001, five computing hubs were established in the Newtown suburb. These were at the local primary school, the community cultural center, NPF, the public library, and the Pacific Island Cultural Center. Four of the centers offered free computing facilities and Internet access from a public location, and at some of the centers introductory computing lessons were available. Thus the project focus was on "communities of place rather than communities of interest" (Pigg and Crank 2004) Such centers provide a "route to inclusion," attracting and involving new users and facilitating a new mode of participative learning within a supportive and stimulating social context (Liff et al., undated, p. 1).

One of the communities of place in the Smart Newtown Project was the Fujitsu computing room, established at the NPF, one of Wellington City Council's largest housing complexes. After 4 years of operation and participation by tenants of the NPF, the Fujitsu room closed and remains so at the time of writing.

This paper examines the events which led to the closure of the Fujitsu room. The author was one of the researchers involved in two separate, contracted Smart Newtown research projects and the design and method used for the projects are described in the next section.

\section{RESEARCH DESIGN}

The first research project (pilot study) was an evaluation of the 1-year pilot, implementation phase, contracted by WREDA. This resulted in a report to the City Council and other key stakeholders (McGregor et al. 2002) that provided recommendations relating to the economic and social inclusion objectives listed earlier. The second project (post study) was funded by Massey University and extended over 2 years of the post-implementation period. The main goal of this project was to investigate sustainability, governance, and management issues, identified from the first study's report as requiring further research. 
A mixed-method design, incorporating both quantitative and qualitative approaches, was adopted for both studies. Data were collected for breadth (user and nonuser surveys) and depth (interviews with key staff, volunteers, and other stakeholders; narratives from users; document analysis). In addition, on-going observation and participation by the three researchers involved in the study added a further dimension to the evaluation. The user survey developed and used in the pilot phase of the project was refined and used again during the post-implementation phase.

The hubs operated on a drop-in basis. It was impossible, therefore, to define a population from which to draw a sample. Potentially the population was the entire Newtown community, although the statistics showed there were participants from outside the immediate Newtown area. The population base for the Fujitsu room was mostly from the NPF. The pilot study resulted in a convenience sample of 118 completed, usable user questionnaires and 159 nonuser survey forms. The nonuser survey was not repeated during the post study phase and the user survey resulted in 111 usable questionnaires. For both studies, a total of 47 interviews were held with volunteers and key stakeholders, and computer users participated in 53 informal narratives and discussions.

\section{THEORETICAL FRAMEWORK}

Warschauer's (2003) model of ICT access for social inclusion provided the theoretical framework for this study. He acknowledges the complicated nature of ICT projects and believes that ICTs and social inclusion intersect. The four sets of resources that Warschauer believes have an iterative relation with ICT use are physical (computers and telecommunication), digital (relevant content in diverse languages), human (literacy and education), and social (community and institutional support). They contribute to effective usage and, once effectively used, feed into promotion and extension of the resources. Warschauer (p. 77) notes that while community computing centers have "embraced" the need to provide the physical resources, such as hardware and telecommunications, there is often implicit reliance on social capital - the norms, trust, and networks thought to exist within the community where the computing center is established.

Important attributes of social capital relate to the personal relations that people have in their family and community which encompass information, influence, social credentials, and reinforcement ( $\operatorname{Lin} 2001$ ). These supportive, emotional, and personal factors can be shared through bonding social capital and bridging social capital (Putnam 2000). The strong ties of bonding social capital result from dense, inward-looking social networks such as among family members and close friends and provide emotional support.

Bridging social capital is associated with large, loose networks over a wider and more diverse group and is considered important for economic and social development. These "weak ties" (Warschauer 2003) are considered important because they provide access to different people, different information, and different social networks beyond our immediate circle.

Tied up with the notion of community is the idea that these strong and weak ties result in networks, norms, and trust, thus enabling members of a community to act together more effectively to pursue shared objectives. Informal gathering places, close 
to home, are considered essential to a community because they create a sense of place, promote companionship, nourish relationships, and encourage sociability (Oldenburg 1991). Oldenburg calls such locations "third places," the first being the home and the second being work.

Another aspect of social capital that Hopkins (2002) discusses is the competitive aspect, experienced by those who struggle for power through control of networks and relationships. She examines other theoretical positions and refers to the French social theorist Pierre Bourdieu, who defines social capital as "the aggregate of the actual or potential resources which are linked to the possession of a durable network of more or less institutionalized relationships of mutual acquaintance and recognition" (Bourdieu 1986, p. 248). Access to these resources varies with the individual and, within the field of social relationships, they struggle to maximize their own access at the expense of others. Social capital has, therefore, the potential for the reproduction of social inequality and social exclusion for those who do not have the advantages and opportunities that accrue through membership in certain communities (McClenaghan 2000). Where there is fragmentation among the community in terms of competing groups for scarce resources, lack of trust and poor network connections between and amongst the groups, the stock of social capital is likely to be very low and the benefits of social capital will not be realized.

Warschauer's model of ICT for social inclusion, the notion of social capital as a critical component in shaping access to technology, and the influence of third place, provide a useful theoretical framework to examine the factors that contributed to the closure of the Fujitsu Computing Room. The next section describes the NPF Fujitsu Room.

\section{THE FUJITSU ROOM}

The NPF house approximately 450 disadvantaged people such as those on low incomes and others who would otherwise struggle to find a safe and secure roof over their heads. A large number of the tenants ( 40 to 50 percent) are state beneficiaries and a few of the residents are housed at NPF as part of their transition into the community after prison terms. Because the majority of the flats are studios and others have only one bedroom, few families are housed in the complex and there is a high transitory tenancy in the flats. The NPF complex is located within an area that has social problems such as graffiti and vandalism of public areas and instances of ethnic gang fighting. The Fujitsu room had a panic button that was monitored 24 hours a day by the Wellington City Council security unit (Smart Newtown Project 2003).

The Fujitsu room initially appeared to have many of the third place characteristics Oldenburg (1991) found to be attractive in encouraging patronage. The room was in an accessible, ground floor location in one of the six blocks of the high-rise complex, thus providing easy, communal access in a quasi-public space. In the early years, there were frequent regulars and little interference from a host, such as a manager or coordinator. The center appeared to have further attributes of a third place: it became a neutral place away from home and work where people felt comfortable, was socially inclusive in terms of participation, and stimulated connection with others. 


\subsection{Human, Social and Physical Resources}

The human, social, and physical resources, identified as essential for effective use of ICTs (Morino 2000; Warschauer 2003), also appeared to be available. There was an unpaid, volunteer coordinator who was an early and enthusiastic supporter of the project and who accepted management responsibilities associated with the computer room. Institutional and financial support was provided from the housing division of the city council, WREDA, and Fujitsu New Zealand Ltd., the organizations responsible for initiating and implementing the project.

The physical resources of 11 computers, printer, application and anti-virus software, on-going help desk, anti-virus protection, and basic maintenance support were provided by Fujitsu. The user interface was in English only. Opening hours were advertised as 10:00 a.m. to 5:00 p.m. weekdays, Saturdays 10:00 a.m. to 8:00 p.m. and Sundays 1:00 p.m. to 5:00 p.m. Some of the volunteers responsible for managing the room would informally assist people new to computing. After 8 months of operation, a polytechnic provided a free, self-paced training program for anyone interested in learning basic computing skills and applications. The polytechnic paid the room coordinator for the class hours (typically averaging 4 hours per week) during which time he was on hand to problem solve and offer users assistance as required. The coordinator received no other payment for his management duties, which included monitoring Internet access to ensure ethical use, establishing and displaying room-use rules, times of opening, volunteer rosters, and so on.

\subsection{Teething Problems}

In the first few months of implementation, there were technical and personnel problems. The volunteer coordinator (who had little computing experience) proved unsuited to manage the facility and these troubles dampened residents' enthusiasm. However, a new volunteer coordinator was recruited who was familiar with computers and proved capable of providing the day-to-day computer support and management necessary to run the environment.

\subsection{Significant Nonuse}

Despite these changes it became apparent, for reasons that were unclear, that there was significant nonuse by tenants. A 17 -question survey was used to establish whether the tenants used the computer room or not and to understand the reasons for nonuse (Crump and McIlroy 2003). The total sample was 159 ethnically diverse people (57 percent of the 275 occupied flats). The majority of respondents ( 69 percent) were aged between 19 and 55 years with 62 percent male, and 38 percent female. Nearly 70 percent stated that they were state beneficiaries.

The results revealed that 73 percent of those surveyed did not use the computer center and the majority ( 75 percent) did not have a home computer or use one elsewhere. A more positive finding was that 78 percent of respondents were aware of the computer 
center's existence but 82 percent of them did not know its opening hours. The nonuser participants were asked if they were interested in using the computer center and, if not, what would encourage them to do so. Only 37 percent indicated interest and the other 63 percent were asked what might encourage them. The participants responded to a number of variables that related to access such as the hours of opening of the computer room, through to social variables such as "someone to go with," and cultural factors such as "ethnic groups only." Five variables related to computer training such as "more classes" and 11 variables explored social aspects that included cultural and gender preferences and attitudes toward computers. The variable most nominated was simply "not interested"; the tenants lacked the motivation to use the computer.

\subsection{Positive Outcomes}

Subsequent to the survey, attendance increased, resulting in positive individual outcomes for the users. While there was a high drop-out rate of those enrolled in the free classes, there were also many who completed the courses. Observation and discussion with the users revealed varied usage of the computers that included study, job hunting, genealogy, games, and Maori culture. Employees of the housing division of the council noted a more positive NPF environment. Graffiti had reduced and there was approximately a 5 percent increase in the NPF occupancy rate because people wanted to live in a complex with a computing facility.

\subsection{Change for the Worse}

However the environment of the Fujitsu room changed gradually for the worse. First, the numbers of volunteers declined, resulting in erratic opening times for the room and occasions when it was closed for days at a time. Second, the coordinator became disillusioned with his unpaid role and there was increasing acrimony among different users and the coordinator. The coordinator had, on numerous occasions, been promised by staff of the Wellington City Council that he would be paid for his work and "the contract would soon arrive." These promises were never made good yet continued to be promised over an 18 to 20 month period. Eventually, he resigned. Third, the computer room opening times were unpredictable, resulting in scheduled classes not running. Fourth, there were occasions when rival gangs fought in the courtyard onto which the computer room opened, resulting in police intervention. Fifth, usage of the computer room dwindled to a very small core group of male users.

The Fujitsu room was no longer the well-functioning third place with Oldenburg's essential criteria of an unobtrusive host and a safe, relaxed, and neutral place away from home where people felt welcome and regularly gathered.

The final, and catalytic, negative change related to the abuse of download volume. It was noted on several observational visits that private laptops were being brought into the room and connected to the system. Subsequently the city council received a statement for a "blow-out" monthly bill (over $\$ 20,000$ ) for the Internet connection cost. This was the catalyst for the room closing and it remains so at the time of writing this paper-just 4 years since its opening. 


\section{ANALYSIS OF REASONS FOR THE CLOSURE}

Reasons for the closure of the Fujitsu center are explored in this section using an analytical framework that includes Warschauer's (2003) model for ICT access and the concept of social capital. As discussed earlier, Warshauer's model specifies the four components of social, human, digital, and physical resources. He considers all four components as essential for effective use of ICT and, if handled well, promoting social inclusion among disadvantaged groups.

\subsection{Social Resources}

Institutional and community resources are the strands that contribute to the social category. Warschauer believes these are critical to community computing projects and analysis shows that, after a mostly positive initial period, deficiencies in three of these resources contributed to the deteriorating situation at the Fujitsu room, ultimately resulting in its closure.

\subsubsection{Institutional}

Short, medium, and long term strategic planning is vital for any project's success and must take into account the context within which the project is situated. The NPF project suffered from a lack of a long-term and well-planned strategy, beyond the pilot phase, which factored in sustainability issues of funding and human resources, especially of volunteers. Fujitsu New Zealand Ltd. met its obligations as defined by the memoranda of understanding between it and the city council. However, interviews with city council staff and councillors reveal that they felt there was too much idealism by individuals originally involved in the project and enthusiasm for the project detracted from council addressing longer-term sustainability issues (especially financial sustainability).

Governance and management issues were problems with the NPF project. There was a lack of champions, particularly a central coordinator responsible for the project overview and liaison among stakeholders. Restructuring of WREDA meant that responsibilities for community ICT initiatives were moved to the city council, with the subsequent loss of the initial champion driver. While some council individuals took a personal interest in the project, there was no official policy, unit, or the high-level backing necessary in the council for community computing projects and, in particular, the NPF project. This situation makes it easier to understand why the coordinator was so shabbily treated with regard to the promises of paid employment. There was an erosion of trust that damaged the relations between council members and the coordinator when the paid contract never eventuated. Trust was further eroded when a different coordinator at another Newtown hub signed a contract for paid employment with the council. This established a "norm of reciprocity" (Putnam 2000, p. 19) between council and the other hub coordinator. The council's actions created inequality, deepened mistrust, and damaged the measure of connectedness between council employees and some of the NPF tenants. 


\subsubsection{Community}

During discussions with the project's stakeholders, the over-dependence on volunteers was identified as an on-going problem and several people said they believed there were unrealistic expectations for the flat volunteers. The very low attendance at the two consultative meetings with tenants of NPF should not have been interpreted as significant community involvement and ownership that would result in a continuing pool of volunteers, especially when there was little evidence of strong social capital with existing networks. The over-reliance on voluntary resources and New Zealand's national and local government policies being biased toward projects rather than process or sustainability has been noted by Williamson and Dekkers (2005).

While there was (and still is) no formal measure of the stock of social capital that existed within the NPF community, it is a reasonable assumption that it would not be high. The transitory nature of tenants, the lack of a tenants' association (that was originally established at NPF but fragmented and then disbanded), and the problems experienced within the NPF means that there would be little evidence of the attributes of social capital, such as norms and trust and a well-functioning network that would be a resource for shared knowledge and ideas and mutually beneficial endeavors (Coleman 1988).

With the benefit of hindsight, there was inadequate institutional support for the NPF community and project, given the context within which the computing room was located. There was insufficient support in fostering community involvement in ICTs and developing social capital and human support networks found by Sipior, Volonino, and Marzec (2001) to be essential elements in successful projects. A review of many community and ICT projects worldwide suggests that, for the establishment of successful ICT initiatives, a critical success factor is the existence of a high level of social capital (Otis and Johanson 2004; Pigg 2001; Simpson 2002).

\subsection{Human Resources}

Warschauer believes the human dimension to be one of the most important factors affecting social inclusion and exclusion. He offers a wide definition for human resources that includes issues such as literacy and education (as well as the particular types of literacy practices that are required for computer use and online communication).

Some users of the Fujitsu room benefitted from working through the self-paced learning program for applications, supported by the volunteer coordinator. There was no quantitative evaluation of the "rates of return to technology use" (DiMaggio and Hargittai 2001, p. 17) but the qualitative data, especially in the initial years of this project, indicate that there was a positive "rate of return" that varied over a range of issues. These related mainly to social benefits that include participation, emotional satisfaction, social capital, learning, and, in a few cases, economic benefit such as users who searched for, and sometimes found, jobs. Numerous tenants and members of the wider Newtown community learned basic computing and Internet skills, thus meeting a number of the objectives specified for the Smart Newtown Project. These included improving educational achievement and interest in participation in further education, development of ICT skill levels among disadvantaged groups, strengthening intra-family 
relationships and cooperation (especially through use of e-mail), improving opportunities for residents, and expression of cultural heritage.

In the early years of the hub's operation, communities of practice were established where people formed networks through being engaged in similar activities and, at the same time, learned from each other. This happened within the more formal context of the self-paced learning program for applications and in the informal groups such as families, similar ethnicities, and sometimes groups (such as an Indian church group) that used the center on a regular basis. The iterative nature of Warschauer's model was evident as some of the learners became volunteers, thus contributing to the sustainability of the hub in terms of reliable opening hours and responsibility for the safety of the room.

Another aspect of human resources which Pinkett and O'Bryant (2003) recommend for community technology and community building initiatives is the engagement of residents as active participants in the implementation process. They report that the process is not easy and requires relationship building, commitment, patience, and empathic listening on all sides. They believe these elements are fundamental to a project's success in order for residents to feel a sense of ownership and empowerment.

\subsection{Digital Resources}

This category refers to online resources: content, language, and overlaps with human resources. For community centers to be effective and useful, "asset mapping" is recommended so that the resources within a community can be leveraged, thus mobilizing them to "facilitate productive and meaningful connections (Pinkett and O'Bryant 2003, p. 192). An example is the immigrant English language classes at a nearby center where the teacher has integrated use of the computers, located in the adjoining classroom, with her lessons. Many of these students, having gained confidence from this blended learning experience, have gone on to attend application classes. Benefits from this include not only graduates with certificates and confidence with ICT but also the provision of a seamless introduction into a wider community, which is often difficult for new immigrants (Crump 2004).

\subsection{Physical Resources}

Of Warschauer's four resources essential for ICT access, the physical resources at the Fujitsu room were the most positive. Fujitsu NZ Ltd. signed memoranda of unerstanding with the council that defined their responsibilities in providing a network of personal computers and a server as well as on-going technical support. There were several equipment upgrades over the operational period.

\section{RECOMMENDATIONS}

What can be learned from this project? Most importantly, cognizance must be taken of the social context within which a community computing center is established. 
Knowledge of the strength (or otherwise) of social capital existing within that community should guide the requirements and considerations needed to achieve sustainability of operation and financial sustainability. Key recommendations for implementing future projects are

- Strategic, long-term planning that commits the provision and level of financial support from institutional bodies. Financial sustainability is vital and requires planning and commitment. Just as the utilities of gas and electricity have become essential, so is knowledge and use of ICTs in this information age. Therefore funding community computing centers in council housing complexes should be viewed as an essential cost to be met by council or other organizations. Because funding is strongly contested across multiple council activities, restricting centers to areas of need and limiting funding to a finite time-frame may make such projects more likely to be accepted by the majority of ratepayers. During the funded period users interested in sustaining the center could be taught how to apply for grants and assisted with seeking funding beyond the set period.

An alternative funding approach is for central government to take responsibility for establishing a national community computing program. The New Zealand digital strategy identifies community as one of the agents of change in becoming a world leader in using ICT. Such a strategy would be congruent with realizing this goal.

- Build social capital. When establishing a computing center in a community with poor networks and where people are disconnected from each other, priority must be given to building social capital. The closed social capital which is built within the community may begin by asset mapping, such as taking an inventory of skills and groups in the community. Bridging social capital could be assisted by working with tenants' associations from neighboring housing complexes and building relations among representatives of the partners involved in the project. New projects should be situated within an established community of activity such as a library or a community center where there are clubs and existing networks. The projects should have clearly stated, measurable goals, be targeted to users' needs (derived from a needs analysis), and, from the outset, have community participation.

- Establish broad ownership. A two-pronged approach needs to be adopted. First, establish multi-sector collaborations that include relationships with corporations, government agencies, nonprofit organizations, neighboring tenants' associations, and universities. Second, residents must be engaged as active participants in the implementation and sustainability process. The NPF community computing initiative may have had greater longevity and fewer resourcing problems had another nearby council housing complex, with an active tenants' association, been involved in the project from the outset.

- Multilevel champions and strong communication. Partnership models with multisector collaborators require relationship management. To facilitate communication and action among the different stakeholders, there needs to be appointment of a 
dedicated coordinator/champion. This person would have responsibility for project management, maintaining and developing community and institutional relationships, and be the central point of contact for the partners. Ideally there will be champions within each organization-a person who has responsibility, and enthusiasm, for the project.

- Relevant content. The relevance of ICT to people's lives must be clearly demonstrated. Once the basic skills of how to use a mouse and keyboard are achieved, a curriculum that is project-based and targeted to users' interests and needs would demonstrate relevancy and provide motivation.

- On-going assessment. A survey of potential users, designed with outcomes in mind, and conducted before implementation would provide valuable insight into the level of social capital already existing in the community and how technology can be made relevant to people's lives. Results of a further survey for comparative purposes would obtain useful data, which could be used to evaluate and measure outcomes and justify further projects.

\section{CONCLUSION}

The theoretical framework used in analyzing events leading to the closure of the NPF computer room has been useful in revealing the social embeddedness of technology. Examination of the use of Warschauer's four key resources shows that low social capital and the inadequate social resources of community and a supporting institution were key factors in the sustainability crisis experienced at the center.

Recent communication with a council employee, who has become involved with the project in latter years, indicates that the closure of this room is not permanent. Currently a strategy is being prepared which firmly places responsibility for funding sustainability with the council. The plan recommends commitment to new community computing initiatives to targeted disadvantaged Wellington communities. The strategy includes the appointment of a community ICT coordinator who will be responsible for the project management and on-going overview of community computing projects. This appointment, together with the employment of a paid on-site Fujitsu room coordinator, is considered crucial for the success of a reopening of the Fujitsu room and the opening of another council housing computing project. The strategy is clearly focused on social inclusion objectives, rather than economic development outcomes. It is "not the result of technological determinism but of the appropriate social construction of technology in a specific and localized context" (Williamson and Dekkers 2005, p. 5). Currently there is no commitment by Fujitsu New Zealand Ltd. to be involved with the reopening of the NPF Fujitsu room. However representatives have indicated a willingness to review the situation to decide if they wish to participate further.

Despite the difficulties experienced with the computing room, many of the project's social objectives have been met. There have been positive outcomes for the individuals who took advantage of the access and acquired skills in ICT - many of whom would otherwise not had the confidence or interest to participate. It remains to be seen whether 
reflection on lessons learned and the level of social capital at the NPF will be sufficient to ensure the sustainability of human and digital resources.

\section{References}

Bourdieu, P. "The Forms of Capital," in J. G. Richardson (ed.), Handbook of Theory and Research for the Sociology of Education, New York: Greenwood, 1986.

Coleman, J. S. "Social Capital in the Creation of Human Capital," American Journal of Sociology, Supplement 94, 1988, pp. S95-S120.

Crump, B. "Immigrants, Language and ICT: Factors for Success in Blended Learning," in Proceedings of Informatics and Research on Women in ICT 2004 International Conference (Volume 2), Kuala Lumpur, Malaysia, July 28-30, 2004, pp. 1175-1184.

Crump, B., and McIlroy, A. "The Digital Divide: Why the "Don't-Want-Tos" Won't Compute: Lessons from a New Zealand ICT Project," FirstMonday (8:12), 2003 (available online at http://www.firstmonday.org/issues/issue8_12/crump/).

DiMaggio, P. J., and Hargittai, E. "From the 'Digital Divide' to 'Digital Inequality': Studying Internet Use as Penetration Increases," Working Paper 19, Center for Arts and Cultural Policy Studies, Woodrow Wilson School, Princeton University, Princeton, NJ, 2001.

Hopkins, L. "What Is Social Capital?," Institute for Social Research Working Papers, No. 2, Swinburne University of Technology, Melbourne, Australia, 2002.

Liff, S., Steward, F., and Watts, P. "Gateways to the Virtual Society: Innovation for Social Inclusion," Ikon, undated (available online at http://users.wbs.ac.uk/group/ikon/research/ gateways).

Lin, N. Social Capital: A Theory of Social Structure and Action, Cambridge, UK: Cambridge University Press, 2001.

McClenaghan, P. "Social Capital: Exploring the Theoretical Foundations of Community Development Education," British Educational Research Journal (26:5), 2000, pp. 565-82.

McGregor, J., Mcllroy, A., and Crump, B. "Report on the Smart Newtown Project," Wellington, NZ: Wellington Regional Economic Development Agency, 2002.

Morino, M. "Policy and Philanthropy: Keys to Closing the Digital Divide," keynote address to the Networks for the People 2000 Conference, Technology Opportunities Program, October 30, 2000 (available online at Morino Institute, http://morino.org/closing_sp_dig.asp).

Oldenburg, R. The Great Good Place, Cafes, Coffee Shops, Community Centers, Beauty Parlors, General Sstores, Bars, Hangouts, and How They Get You Through the Day, New York: Paragon House, 1991.

Otis, N., and Johanson, G. "Community Sustainability and Information and Communications Technologies: Current Knowledge and Recent Cases," paper presented at the Australian Electronic Governance Conference, Center for Public Policy, University of Melbourne, April 14-15, 2004.

Pigg, K. "Applications of Community Informatics for Building Community and Enhancing Civic Society," Information, Communication and Society (4:4), 2001, pp. 507-527.

Pigg, K. E., and Crank, L. D. "Building Community Social Capital: The Potential and Promise of Information and Communications Technologies," The Journal of Community Informatics (1:1), 2004 (http://www.ci-journal.net/viewissue.php?id=3).

Pinkett, R., and O'Bryant, R. "Building Community, Empowerment and Self-Sufficiency," Information, Communication and Society (6:2), 2003, pp. 187-210.

Putnam, R. Bowling Alone: The Collapse and Revival of American Community, New York: Simon and Shuster, 2000.

Simpson, L. "Big Questions for Community Informatics Initiatives: A Social Capital Perspective," in Proceedings of the Search Conference: Community and Information Technology: 
The Big Questions, Melbourne, Center for Community Networking Research, Monash University, October 16, 2002 (http://www.ccnr.net/searchconf/simpson.htm).

Sipior, J. C., Volonino, L., and Marzed, J. Z. "A Community Initiative that Diminished the Digital Divide," Communications of the Association for Information Systems (13), 2001, pp. 29-56,

Smart Newtown Project. Submission by Wellington City Council, Fujitsu NZ Ltd., Wellington Regional 2020 Communications Trust, Positively Wellington Business and Smart Newtown, Wellington: Positively Wellington Business, 2003.

Warschauer, M. Technology and Social Inclusion: Rethinking the Digital Divide, Cambridge, MA: The MIT Press, 2003.

Williamson, A., and Dekkers, J. "ICT as an Enabler in the Community and Voluntary Ssector in Aotearoa/New Zealand," in G. Irwin, W. Taylor, A. Bytheway, and C. Strumpfer (eds.), Proceedings of the Community Informatics Research Network 2005 Conference, Cape Town, South Africa: Community Informatics Research Network, 2005, pp. 408-429.

\section{About the Author}

Over the past six years Barbara Crump has been involved in evaluating the Smart Newtown Project, a community computing digital divide initiative in Wellington. She continued this interest when she was appointed Visiting Scholar at the University of Malaya, Kuala Lumpur, in 2004. Another focus of her research is investigating reasons for the low participation of women in tertiary computing programs and their involvement in the IT industry. This has led to a commissioned national study of women in the IT workforce that was replicated in Selangor State and Kuala Federal Territory, Malaysia. Barbara is a senior lecturer in the Department of Information Systems at Massey University, Wellington, and may be contacted at b.j.crump@massey.ac.nz. 